\title{
Analysis of antimicrobials' consumption profile in a University Hospital of Western Paraná, Brazil
}

\author{
${\text { Luciane de Fátima Caldeira }{ }^{1 *} \text {, Marcelo Nascimento Burattini² }}^{2}$
}

\author{
${ }^{1}$ Department of Hospital Pharmacy, Faculty of Pharmacy, State University of Western Paraná, ${ }^{2}$ Department of Medicine, \\ Federal University of São Paulo
}

\begin{abstract}
The objective of this study was to analyze the variation in antimicrobials' consumption and the costs related to their use at a University Hospital between 1999 and 2004. The annual consumption of nine antimicrobials, expressed in DDD/100 patients-day, and the direct costs with their acquisition were evaluated. Analysis of variance and regression techniques were used to compare data, considering a significance level of 5\%. The most consumed antimicrobials were amikacin and ceftriaxone. In general, antimicrobials consumption, expressed in DDD/100 patients-day, increased from 9.21 in 1999 to 25.08 in 2004 ( $p \leq 0.0001)$. When analyzing antimicrobial consumption as related to specific hospital units, the ICU showed the highest consumption followed by Chemotherapy and Medical Clinical units, respectively. In addition, the number of patients-day increased from 2671/month in 1999 to 3502/month in 2004, $p \leq 0.0001$. As a consequence, total expenditure with antimicrobials increased from $\mathrm{R} \$ 98.89$ per 100 patients-day in 1999 to $\mathrm{R} \$ 731.26$ in 2004, $p \leq 0.0001$. Between 1999 and 2004 significant increases in both consumption and financial expenditure with antimicrobials were observed.
\end{abstract}

Uniterms: Medicines/Defined Daily Doses. Medicines/utilization. Antimicrobials/consumption Pharmacoepidemiology.

O trabalho teve por objetivo analisar a variação do consumo e gastos financeiros com antimicrobianos em Hospital Universitário entre 1999 e 2004. Analisou-se 9 antimicrobianos, sendo o consumo expresso em DDDs/100 pacientes-dia e o preço médio de compra obtido do relatório da farmácia hospitalar. As variações anuais no consumo, o consumo por tipo de unidades de internação e gastos com cada antimicrobiano foram estudadas por análise de variância. Adotou-se 5\% como limiar de significância. Os antimicrobianos mais consumidos no período foram amicacina e ceftriaxona. Observou-se aumento no consumo dos antimicrobianos selecionados de 9,21 DDDs/100 pacientes-dia em 1999 para 25,08 em 2004 ( $\mathrm{p} \leq 0,0001)$. Entre as unidades de internação, a UTI apresentou o maior consumo médio, seguindo-se as unidades de Quimioterapia e Clínica Médica. A média mensal de pacientes-dia atendidos aumentou de $2671 \mathrm{em} 1999$ para $3502 \mathrm{em} 2004$ ( $\mathrm{p} \leq 0,0001)$. Observou-se aumento significativo nos gastos totais com antimicrobianos no período ( $\mathrm{R} \$ 98,89$ x R $\$ 731,26$ por 100 pacientes-dia entre 1999 e $2004, \mathrm{p} \leq 0,0001$ ). Observou-se aumento significativo tanto na utilização quanto no gasto financeiro por 100 pacientes-dia diretamente relacionado à aquisição dos antimicrobianos estudados.

Unitermos: Medicamentos/Dose Diária Definida. Medicamentos/uso. Antimicrobianos/consumo. Farmacoepidemiologia.

\section{INTRODUCTION}

One of the main world preoccupations respecting to medications use is related with antimicrobial therapy

\footnotetext{
*Correspondence: L. F. Caldeira. Universidade Estadual do Oeste do Paraná - Unioeste. Rua Universitária, 1.619 - Jardim Universitário - Caixa Postal 701 - 85819-110 - Cascavel - PR, Brazil. E-mail: luciane-caldeira@hotmail.com
}

(Castro et al., 2002). The irrational use of antimicrobial medications in hospital environments brings consequences not only in costs, but also problems related with increase in microorganisms' resistance, fostering to superinfection, higher risk for side effects, and "covering" of infectious diseases (Borges Filho et al., 2005).

With all changes in microorganisms resistance profile, it is necessary the growing use of more and more po- 
werful antimicrobial medications, generating so a vicious cycle; besides other problems, such as cost and duration increase of hospital admissions, (Fernades, Fernandes, Ribeiro Filho, 2000; Gould, 2002). Currently, the conception of rational use of antimicrobial agents has been envisaged as a primordial strategy for the control of dissemination of antimicrobial resistance. The control of antimicrobial agents in hospitals presupposes the knowledge about the situation of these medications consumption, using an adequate methodology and adopting uniform criteria for such a purpose, which should be derived from studies about these medications utilization (Laporte, Tognoni, 1993; Ena, 1997; López-Medrano et al., 2005).

Studies involving the use of antimicrobial agents in certain hospital areas could be utilized to determine standards and trends of use, connecting then such information to antimicrobial resistance (Loeffler et al., 2003). The rational use of medicines could be defined as the employment of the adequate medication, with assured quality, in the lower therapeutic dose as possible, minimizing so the occurrence of adverse effects and maximizing the beneficial effects, with the lower cost as possible (Laporte, Tognoni, Rosenfeld, 1989). A program of supervision of antimicrobial agents use is essential in hospitals, in order to improve the prescription of antimicrobial agents and decrease hospital costs.

The pharmacoepidemiological analysis allows to quantify the current use of a selected medicine, outline its use profile respecting to time, determine if its respective utilization habits correspond to current status of knowledge, identify possible reasons contributing for its consumption oscillations, and give support to implementation of measures favoring the adequate utilization of medicines (Lee, Bergman, 1994).

The Defined Daily Dose (DDD) is a technical measurement that standardizes the actual consumption of medicines, based on the drug's average daily dose for its main adult indication, in a period of 24 hours (Capellã, Laporte, 1994). The purpose of this present work is to analyze the utilized antimicrobial agents at the University Hospital of Western Paraná (Hospital Universitário do Oeste do Paraná - HUOP) and in some of its admission units, as well as analyze the actual expenses with the consumption of these drugs, in the period of 1999 to 2004.

\section{METHODS}

The study was developed in the University Hospital of Cascavel linked to State University of Western Paraná (Universidade Estadual do Oeste do Paraná - UNIOESTE), in the period of 1999 January to 2004 December. It is a public hospital with approximately 150 beds, distributed in admission units of diverse specialties such as general practice, medical clinic, surgical and pediatrics, gynecologic and obstetric, oncologic, intensive care units (clinical and surgical), first aid and other areas of attendance.

This is a retrospective study, based on consumption records of selected antimicrobial agents, prescribed for the adult patients' population of HUOP, which has utilized the DDD to normalize the information referring to antimicrobial agents' consumption in different hospital units and different years of study. The consumption data referring to hospital as a whole were analyzed, as well as the consumption data specific for some admission units.

Infirmaries of several medical specialties were included in the study, being that some of them were grouped and others were studied separately. Between the hospital units grouped for this study, the units of medical clinic, temporary attendance and general practice were jointly named as "medical clinic", due to similar characteristics in the patients admitted by these units, for diverse clinical treatments. The group composed by the gynecologic and obstetric clinic, in conjunction with the obstetric center, was named "obstetric clinic". The intensive care unit, chemotherapy unit and surgical clinic were studied separately. The units of orthopedic and neurologic clinic, first aid and surgical center were excluded from the study, due to inconsistence of data related to number of patients-day and consumption of antimicrobial agents.

For this study, nine antimicrobial agents were selected; the majority of them being subjected to control by the Commission of Control of Hospital Infection (Comissão de Controle de Infecção Hospitalar - CCIH) and the remaining ones, clearly presenting great consumption in the hospital. The control of antimicrobial agents is developed by the Service of Control of Hospital Infection (Serviço de Controle de Infecção Hospitalar - SCIH) and the Service of Hospital Pharmacy, through a releasing card for antimicrobial agents of restrict use. The selected antimicrobial agents were: amikacin, cefotaxime, ceftazidime, ceftriaxone, ciprofloxacin, clindamycin, imipenem/cilastatin, oxacillin and vancomycin.

The quantity of utilized flasks of every analyzed antimicrobial agent was provided by the HUOP pharmacy, through electronic reports of monthly consumption issued by the program of stock control of the service of hospital pharmacy; and these reports were issued for the hospital as a whole, as well as for every selected admission unit. The quantities provided were converted into grams of every antimicrobial agent, according to their respective commercial presentations consumed. The data referring to the number of occupied beds and the rate of yearly beds 
occupation were obtained from the hospital Service of Medical File and Statistics (Serviço de Arquivo Médico e Estatística - SAME).

The analysis of consumption of antimicrobial agents was developed utilizing the DDD, normalized for 100 patients-day, as a reference measurement. The values of DDD for every antimicrobial agent were adapted from the table utilized by Monnet and Sorensen (1999). After the conversion from the consumption in grams to every antimicrobial agent DDD, it was calculated the number of DDDs normalized for 100 patients-day for every antimicrobial agent and month along the study period, utilizing the following formula (Lawton et al., 1999; Hidalgo, 2006):

$\mathrm{DDD} / 100$ patients-day $=\frac{\text { DDD Number }}{\text { Number of Patients-day }} \times 100$

Where the number of patients-days was obtained from the relation

Number of Patients - day $=\mathrm{O} \times \mathrm{N} \times \mathrm{T}$,

with: $\mathbf{O}=$ specific rate of beds occupation of the service; $\mathbf{N}=$ number of available beds; $\mathbf{T}=$ time period in days.

So defined, the number of DDDs per 100 patientsday was utilized in this study to analyze the consumption variation in the selected antimicrobial agents.

To evaluate the financial costs referring to antimicrobial agents consumption in the hospital as a whole, it was utilized the purchase price contained in the report of consumption of medications from the program of stock control of hospital pharmacy.

The consumed quantity of every analyzed antimicrobial agent, in grams, jointly with the number of patientsday, were stored in an electronic worksheet utilizing the software Excel ${ }^{\circledR} 5.0$, to calculate the number of DDDs/100 patients-day. The statistical analyses were developed utili- zing the statistical package Statistica ${ }^{\circledR} 4.5$, for Windows ${ }^{\circledR}$. The monthly averages of both, DDDs/100 patients-day and every year number of patients-day, were compared by variance analysis (ANOVA). The temporal variation trend of variables of interest was analyzed by linear regression, being adopted as significance limit, in both cases, $\alpha \quad 0.05$.

\section{RESULTS}

Table I presents the monthly average of the number of patients-day admitted at HUOP during every year of study period, as well as the yearly total of attended patients-day, with exception of pediatric units beds, because it is not possible to define the Defined Daily Dose for pediatric patients, once the drug daily posology is a function of patient's weight.

During the period of 1999 to 2004, it was observed an increase of approximately $30 \%$ in the monthly average and yearly total of attended patients-day ( $p \leq 0.0001)$, but the yearly average of staying rate was stable in the studied period.

To quantify the general consumption of selected antimicrobial agents at HUOP, the monthly averages of DDDs/100 patients-day were calculated for every selected antimicrobial agent for year of study (Table II).

The most consumed antimicrobial agents at HUOP, in the period of this study, were amikacin and ceftriaxone. Besides, it is possible to observe a gradual increase in the consumption of several antimicrobial agents, such as ceftriaxone, ceftazidime, ciprofloxacin, clindamycin and imipenem (Table II). In the same period, amikacin has shown increase in consumption until the year of 2001, when the higher DDDs/100 patients-day (8.98) occurred; then, the DDDs/100 patients-day has fallen to approximately 6.5 and maintained stability in the following years.

Respecting to imipenem/cilastatin, the higher consumption was observed in the year of 2004, with monthly average of 1.26 DDDs/100 patients-day.

TABLE I - Number of attended patients-day and yearly average of staying at University Hospital of Western Paraná

\begin{tabular}{lccc}
\hline Year & Average of patients-day/month & Total of patients-day/year & Time of staying (days) \\
\hline 1999 & 2671 & 32052 & 4.67 \\
2000 & 2741 & 32892 & 4.48 \\
2001 & 2750 & 33000 & 4.70 \\
2002 & 3341 & 40092 & 4.82 \\
2003 & 3645 & 43740 & 4.76 \\
2004 & 3502 & 42024 & 4.88 \\
\hline $\boldsymbol{P}$ & & $\mathbf{0 . 0 0 0 1}$ & $\mathbf{0 . 5 2 3 9}$
\end{tabular}


TABLE II - Variation in the average monthly consumption in DDDs/100 patients-day of nine analyzed antimicrobial agents at HUOP, in the period of 1999 to 2004

\begin{tabular}{lccccccc}
\hline Antimicrobial agents & $\mathbf{1 9 9 9}$ & $\mathbf{2 0 0 0}$ & $\mathbf{2 0 0 1}$ & $\mathbf{2 0 0 2}$ & $\mathbf{2 0 0 3}$ & $\mathbf{2 0 0 4}$ & $\boldsymbol{p}^{*}$ \\
\hline Amikacin & 3.45 & 4.88 & 8.98 & 6.85 & 6.28 & 6.63 & $\mathbf{0 . 0 0 2 1}$ \\
Cefotaxime & 0.04 & 0.05 & 0.04 & 0.29 & 0.09 & 0.35 & 0.1024 \\
Ceftazidime & - & - & 0.18 & 0.33 & 1.19 & 1.35 & $\mathbf{0 . 0 2 0 9}$ \\
Ceftriaxone & 2.57 & 3.15 & 5.20 & 6.23 & 7.27 & 8.32 & $\leq \mathbf{0 . 0 0 0 1}$ \\
Ciprofloxacin & - & - & - & 0.55 & 0.65 & 1.56 & $\leq \mathbf{0 . 0 0 0 1}$ \\
Clindamycin & - & - & 0.92 & 1.27 & 1.93 & 2.67 & $\mathbf{0 . 0 0 4 1}$ \\
Imipenem/Cilastatin & 0.32 & 0.37 & 0.57 & 0.43 & 0.51 & 1.26 & $\leq \mathbf{0 . 0 0 0 1}$ \\
Oxacillin & 2.27 & 1.39 & 1.94 & 3.96 & 1.99 & 1.44 & $\mathbf{0 . 0 0 0 7}$ \\
Vancomycin & 0.56 & 0.53 & 1.42 & 0.62 & 0.93 & 1.50 & $\mathbf{0 . 0 3 2 6}$ \\
\hline TOTAL & $\mathbf{9 . 2 1}$ & $\mathbf{1 0 . 3 7}$ & $\mathbf{1 9 . 2 5}$ & $\mathbf{2 0 . 5 3}$ & $\mathbf{2 0 . 8 4}$ & $\mathbf{2 5 . 0 8}$ & $\mathbf{0 . 0 4 3 6}$ \\
\hline
\end{tabular}

* ANOVA: comparison of monthly averages of consumption, expressed in DDD/100 patients-day, for every analyzed antimicrobial agents and year.

The oxacillin, which was between the most utilized antimicrobial agents at study starting, presented relatively constant consumption along the study period, except for the year of 2002, justifying so the difference observed in the consumption of this antimicrobial agent in the period ( $p=0.0007$ ), but without trend for defined increase or decrease. The vancomycin maintained a similar consumption standard in the years of 1999, 2000 and 2002. However, it is possible to observe an important increase in the
DDDs/100 patients-day in the years of 2001, 2003 and 2004. On the other hand, the consumption of cefotaxime was maintained constant.

Figure 1 presents the temporal evolution of total consumption of studied antimicrobial agents at HUOP, grouped per attending units as defined previously. Such procedure has enabled a better visualization of the variation in the global consumption of antimicrobial agents, in every attending unit of HUOP.

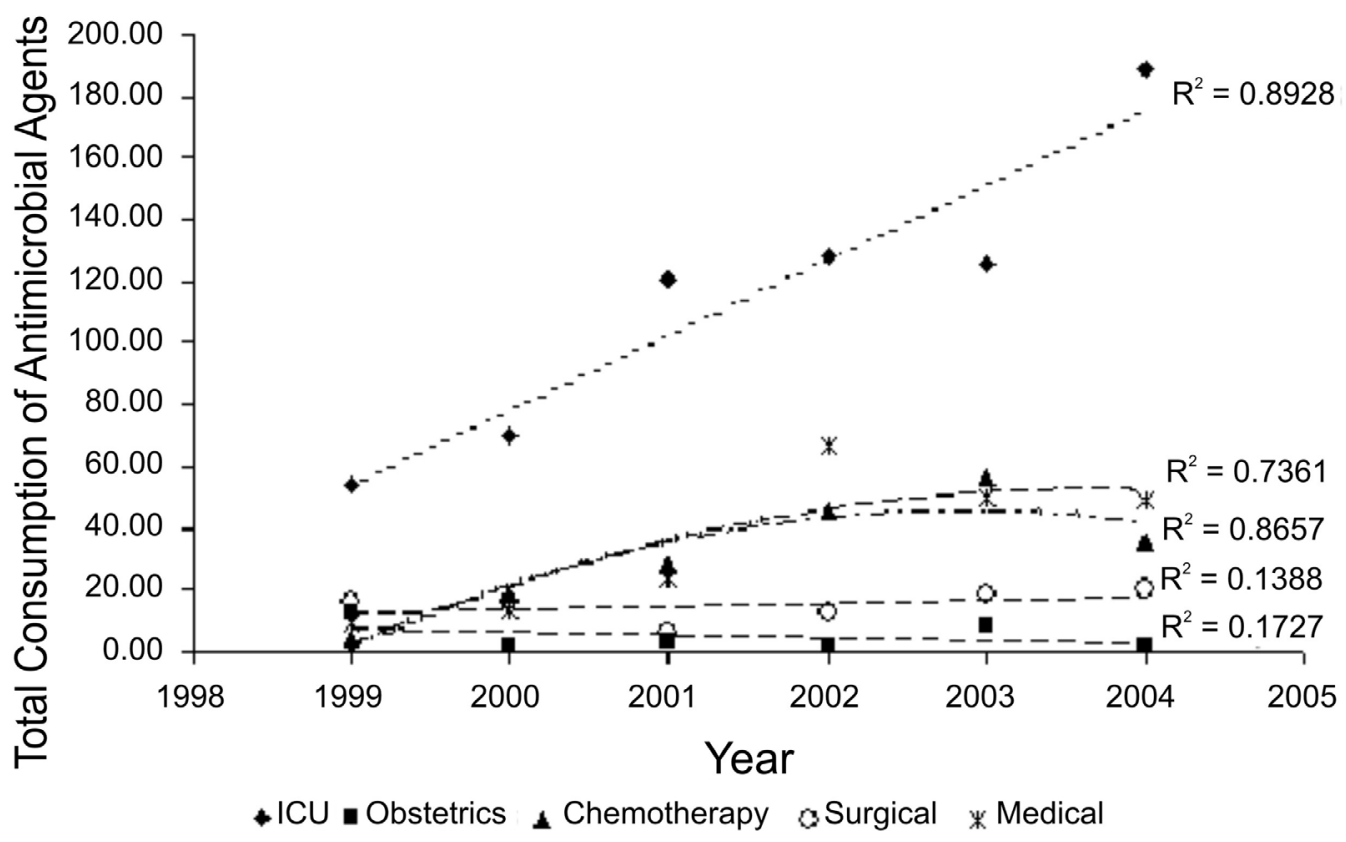

FIGURE 1 - Monthly average of total consumption of selected antimicrobial agents (expressed in DDDs/100 patients-day) utilized per admission unit of HUOP, in the study period. 
It is observed an increase in the monthly average consumption of selected antimicrobial agents, expressed in DDDs/100 patients-day, along the 6 years of study in all hospital units, except for Obstetric and Surgical units (Figure 1). The analysis of variance in the consumption of antimicrobial agents, taking into account the factors time and admission unit, has demonstrated significant difference between the units and along the time (ANOVA, $p<0.0001$ for both factors).

The Intensive Care Unit has presented the higher monthly average consumption of selected antimicrobial agents and also the higher consumption increase along the time, without trend to stabilization yet.

For the remaining attending units, the consumption variation of antimicrobial agents in the study period is less marked. The Chemotherapy and Medical units presented very similar behavior respecting to antimicrobial agents consumption, with important increase until 2002, but a trend to stabilization in 2003 and 2004. The consumption of antimicrobial agents in the surgical and obstetric units varied a little, along the study.

For the calculation of financial impact, it was utilized a non linear regression analysis. Figure 2 demonstrates the yearly values, in reais $(\mathrm{R} \$)$, spent with the 9 selected antimicrobial agents, utilizing for the calculation the average purchase price of every flask of antimicrobial agent, in the studied period.

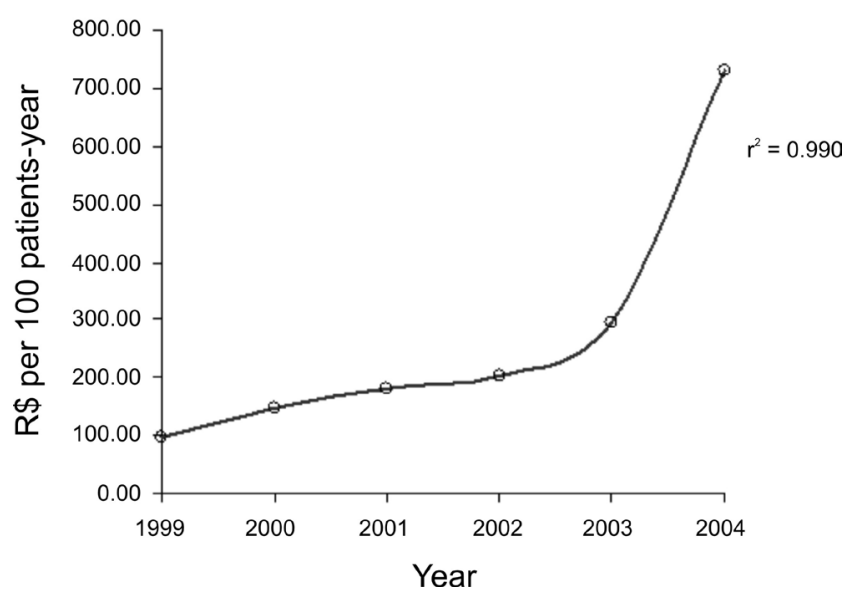

FIGURE 2 - Analysis of total yearly expenditure with the antimicrobial agents studied at HUOP, in the period of 1999 to 2004 .

The Figure 2 illustrated a yearly variation of global expenditure with antimicrobial agents per 100 patientsday, verified at HUOP in the studied period. It is observed an increase in the direct expenditures with antimicrobial agents, which is approximately linear between the years of 1999 and 2003, corresponding to an increase in the consumed quantity, expressed in DDD/100 patients-day, and an increase in the quantity of attended patients-day at HUOP, in the period. However, the increase of expenditures with antimicrobial agents verified in 2004, respecting to remaining years, could not be explained in such a way, because the total expenditure was larger than the double of which would be expected, taking into account the verified increase in the global consumption of antimicrobial agents in $\mathrm{DDD} / 100$ patients-day weighed by the increase in the attendances volume (in patients-day) verified in the period. We did not find a plausible justification for this increase.

\section{DISCUSSION}

The excessive use of antimicrobial agents and the low adherence to measures for infection control have been identified as important factors for the increase of microbial resistance in the hospital environment. Studies have demonstrated the utilization of antimicrobial agents in approximately $50 \%$ of admitted patients, which amounts almost $50 \%$ of hospital pharmacy budget; but with these antimicrobial treatments being inadequately utilized in $30 \%-70 \%$ of times, due to incorrect choice of drug, dose or treatment duration (Murthy, 2001; Shankar et al. 2003; Cook, 2004; López-Medrano, 2005).

In the individual analysis of antimicrobial agents utilized at HUOP in the period of this study, the most consumed were amikacin and ceftriaxone. The ceftriaxone consumption has increased from $2.57 \mathrm{DDDs} / 100$ patientsday in the year of 1999 to 8.32 DDDs/100 patients-day in the year of 2004, as observed at Table II. Similar results were found by Hidalgo (2003), with the cephalosporin group representing the antimicrobial agents of higher consumption at the São Paulo Hospital, in São Paulo, Brazil; with ceftriaxone standing out within this group. Borges et al. (2005) have also verified that ceftriaxone was the cephalosporin of higher consumption in 2005 at the Municipal Hospital of Contagem, Minas Gerais, Brazil (8.3 DDDs/100 beds-day).

The ceftazidime and clindamycin (Table II) presented, from the year of 2001, a constant increase in consumption. The same antimicrobial agents analyzed by Nájera et al. (2003) in a general hospital in Spain, presented a different behavior from the one found in our study. These authors verified that these two antimicrobial agents did not follow a trend for consumption increase in the period of 1996 to 2000 . The ceftazidime presented higher consumption in the years of 1996 (0.812 DDD/ 100 beds-day) and 1998 ( $0.726 \mathrm{DDD} / 100$ beds-day), with fall in consumption in the years of 1997 (0.443 DDD/100 beds-day) and 1999 (0.401 DDD/100 beds-day). Carling 
et al.(2003), in a prospective study developed in a school hospital in Boston, observed that the clindamycin consumption maintained constant $(2.25 \mathrm{DDD} / 100$ patientsday, varying from 1.72 to 2.65 ).

Respecting to ciprofloxacin, the unique quinolone included in this study, and whose use at HUOP has started in 2002, it was observed a continuous increase in the monthly average consumption in DDDs/100 patients-day (Table II). These results are similar to those found by Nájera et al. (2003), in which the consumption of this antimicrobial agent, as of parenteral as oral use, presented progressive increase in the period of 1996 to 2000. On the other hand, Cook et al. (2004), worried with the increase of microbial resistance in a tertiary school hospital in North Carolina (USA), implemented a multidisciplinary program for control of broad-spectrum antimicrobial agents, suggesting rationalization or the interruption in the use of antimicrobial agents. This intervention reduced the consumption of ciprofloxacin from $12.40 \mathrm{DDD} / 100$ patients-day in the year of 2000 to 8.93 in the year of 2001 .

The consumption of imipenem/cilastatin at HUOP was higher in the year of 2004 (1.26 DDDs/100 patientsday). Still in the study of Cook et al. (2004), the control program of antimicrobial agents caused a decrease in the consumption of imipenem/cilastatin from 1.12 DDD/100 patients-day in 2000 to 0.43 in $2001(p=0.01)$. Oliveira (2002) has also noticed a decrease in the imipenem consumption in the University Hospital of Triângulo Mineiro, in Uberaba. This drop was attributed to the starting of the control program of use of antimicrobial agents implemented in the institution, in 1998.

Respecting to consumption of oxacillin, the marked increase in consumption of this antimicrobial agent in the year of 2002 (Table II) has drawn the attention. This increase could be due to a restriction in use of vancomycin, which presented a high consumption in the year of 2001 . This can be observed at Table II, where the vancomycin presents consumption about 3 times higher in that year, as compared to years of 2000 and 2002. Hidalgo (2003) has also observed excessive use of vancomycin, in 2001, at São Paulo Hospital; which was attributed to high prevalence of oxacillin-resistant staphylococcus. Besides, it was observed in this institution the appearance of vancomycin-resistant enterococci and intermediate vancomycin-resistant staphylococci (VISA).

The consumption of antimicrobial agents in ICUs is differentiated as compared with other admission units; this is due to clinical characteristics of these units' patients, whom in their majority are under critical and immunodepressed conditions; the high complexity of therapeutic and diagnostic procedures developed over there; and selective pressure by the use of antimicrobial agents, contributing so for a higher frequency of resistant microorganisms (Murthy, 2001).

In this study, respecting the monthly average consumption of antimicrobial agents expressed in DDDs/100 patients-day in the admission units, the ICU has shown higher consumption, being followed by the units of Chemotherapy and Medical Clinic (Figure 1).

Nájera et al. (2003) have evaluated the global consumption of antimicrobial agents in all hospital sectors, and also such consumption at ICU, but analyzing it separately. During the 5 years of study, the total consumption of antimicrobial agents was of 59.469 DDDs/100 beds-day, but when analyzing separately the ICU consumption, it was of 176.162, that is, a specific consumption 3 times higher as compared to global consumption. These data are compatible with our findings (Figure 1).

The Chemotherapy Unit is an outsourced sector within HUOP, being administered by a philanthropic entity named Western Paraná Union of Combat to Cancer (União Oeste Paranaense de Combate ao Câncer - UOPECCAN). All patients with treatments for diverse types of neoplasias requiring hospital admission are forwarded for this sector at HUOP. Because it is an outsourced sector, the majority of medications utilized by its patients are purchased with resource from the entity itself. Medications from the HUOP hospital pharmacy were used only, when UOPECCAN had not such medicines available in its stock. Thus, some antimicrobial agents utilized in the Chemotherapy Unit were from HUOP pharmacy; being, therefore, object of this study. It is observed at Figure 1 that the monthly average consumption of antimicrobial agents in this unit, in DDDs/100 patients-day, has presented a practically linear increase in the period between 1999 and 2003. However, draws the attention the year of 2004, in which a decrease of antimicrobial agents consumption occurred, as compared to previous two years; supposedly, it was due to an increase in the acquisition of antimicrobial agents by the philanthropic entity itself, leading to a decrease in the utilization of these medicines by the HUOP hospital pharmacy.

The HUOP unit of medical clinic attends patients of diverse clinical pathologies, between them, patients immunosuppressed and bearing infectious syndromes. Due to complexity of these patients, it is expected a high consumption of broad-spectrum antimicrobial agents, corresponding to observed at Figure 1, which shows a consumption equivalent to that of chemotherapy unit.

When analyzing the general consumption of all selected antimicrobial agents for this study, it is possible to observe a very important increase in the normalized 
consumption year after year, passing from 9.21 DDDs/100 patients-day in 1999 to 25.08 in 2004, which represents an increase of almost 3 times in 6 years ( $p=0.0436$, Table II).

An increase in the antimicrobial agents consumption was also observed in a university hospital of Porto Alegre. The average consumption of antimicrobial agents has increase from 83.8 to $124.58 \mathrm{DDDs} / 100$ beds-day in an interval of 6 years (Castro et al., 1999). On the other hand, a study developed by Hidalgo (2003) has shown consumption stability of 14 antimicrobial agents in the analyzed period at São Paulo Hospital, which counts on an acting Commission of Rationalization of Use of Antimicrobial Agents, with more than a decade from its implementation.

According to Follador (2005), pharmacoeconomics is a tool to be added to rational use of medications. If medications are utilized with precise indication, in the correct form, and following the better decision criteria between benefits and risks, a good dose of economy will be already being applied.

In this study, only the expenses referring to consumption of antimicrobial agents at HUOP, in the studied period, were considered. The economic analysis observed, did not target the evaluation of cost-benefit, costeffectiveness, or even cost minimization. The economic factor served only to represent the financial impact with the consumption of nine selected antimicrobial agents in this institution (Figure 2).

It is important to emphasize the utilization of an average purchase price for the analyzed antimicrobial agents, coming from the consumption report of stock control provided by hospital pharmacy. In this way, some hypotheses could be raised to justify the great increase evidenced in the expenditure with antimicrobial agents, such as: irregularity in the launch of purchase price of these drugs; emergency purchases of antimicrobial agents without public tender, with the drugs being acquired from drugstores, favoring cost increases; increase in the consumption of more expensive drugs, such as, for instance, ciprofloxacin, imipenem/cilastatin and vancomycin resulting from the assistance provided to patients in more critical status; general increase of antimicrobial agents consumption in the study period, over all in the year of 2004; and, ultimately, constant increase in the yearly average number of attended patients-day.

It should be emphasized, however, that the three latter factors, probably, explain only part of the verified increase in the expenditures, as the increase of average consumption per 100 patients-day, even if corrected by the increase in the volume of attendances, is lower than the verified increase of expenditures. The two main hypotheses, despite probable, are more difficult to verify.

Hidalgo (2003), analyzing the profile of utilization of 14 antimicrobial agents in the São Paulo Hospital, observed significant drop in the expenses with these drugs, in the study period. This is due, probably, to the work developed in the institution through the program of rationalization of use of antimicrobial agents, which contributed for the maintenance and stabilization of consumption, even taking into account the introduction of newer antimicrobial agents, with higher cost and the increase in levels of resistance to antimicrobial agents in the institution.

Cavalcante et al. (2005), through the elaboration and development of the Program of Rationalization of Antimicrobial Agents developed by the executor group of CCIH of Mário Covas State Hospital, in Santo André, Brazil, evaluated the prescription of antimicrobial agents of restrict use, between them, ceftazidime, ciprofloxacin, imipenem and vancomycin. Out of 503 analyzed prescriptions, economy was verified in $18.8 \%$, representing about $\mathrm{R} \$ 68,139.52$ in the costs of these drugs.

In brief, the consumption of antimicrobial agents increased significantly in the institution, during the studied period. It is supposed that the high consumption of antimicrobial agents evidenced in this study, is due to prescription habits, inadequacy in the adherence to norms of appropriate use, little experience in pharmacovigilance programs and the complexity of developed hospital procedures.

In this way, this study benefits not only the HUOP, but also other teaching institutions, in the sense to address policies for controlled use of antimicrobial agents, as well as to help the administrative sector in the budgetary prevision for these medicines purchase scheduling, and mainly to review the control measures of hospital infection and the rational use of antimicrobial agents. The knowledge of these medicines consumption standards provides arguments to improve the use rationalization of antimicrobial agents within the institution.

\section{REFERENCES}

BORGES FILHO, G. M.; MOREIRA, P.A.; VIEIRA, L.S.; BETTCHER, L.; COSTA, M.L.; REIS, A.M.M. Evolução do consumo de antimicrobianos no Hospital Municipal de Contagem/MG. Braz. J. Infect. Dis., v.9, supl.1, p.88, 2005.

CAPELLÃ, D.; LAPORTE, J.R. Métodos empregados em estudos de utilização de medicamentos. In: LAPORTE, J.R.; TOGNONI, G.; ROZENFELD, S., (Eds). Epidemiologia de medicamentos. Princípios gerais. São Paulo: HucitecAbrasco, 1994. p.95-113. 
CARLING, P.; FUNG, T.; KILLINO, A.; TERRIN, N.; BARZA, M. Favorable Impact of a Multidisciplinary Antibiotic Management Program conducted during 7 years. Infec. Control. Hosp. Epidemiol., v.24, n.9, p.699-705, 2003.

CASTRO NETO, M. Bactérias Multirresistentes. In: COUTO, R.C.; PEDROSA, T.M.G.; NOGUEIRA, J.M., Eds. Infecção hospitalar-epidemiologia e controle. 2.ed. Rio de Janeiro: Medsi, 1999. cap.26, p.383-392.

CASTRO, M.S.; PILGER, D.; FERREIRA, M.B.C.; KOPITTKE, L. Tendências na utilização de antimicrobianos em um hospital universitário, 1990-1996. Rev. Saúde Pública. São Paulo, v.36, n.5, p.553-558, 2002.

CAVALCANTE, A.J.W.; FOGAÇA, V.B.; RAIHER, S.; SANTOS, R.S.; PAGASSINI, P.A.E.; HALLAGE, N.M. Análise das prescrições de antimicrobianos no Hospital Estadual Mário Covas. Braz. J. Infect. Dis., v.9, supl.1, p.161, 2005.

COOK, P.P.; CATROU, P.G.; CHRISTIE, J.D.; YOUNG, P.D.; POLK, R.E. Reduction in broad-spectrum antimicrobial use associated with no improvement in hospital antibiogram. $J$. Antimicrob. Chemother.,v.53, p.853-859, 2004.

ENA, J. Optimal use of antibiotics. In: WENZEL, R.P. (Ed.). Prevention and control of nosocomial infections. 3.ed. Baltimore: Willians \& Wilkins, 1997. cap.19, p.323-338.

FERNANDES, A.T.; FERNANDES, M.O.; RIBEIRO FILHO, N. Infecção Hospitalar e suas interfaces na área de saúde. São Paulo: Editora Atheneu, 2000. 1721 p.

FOLLADOR, W. Farmacoeconomia aplicada. In: MAIA NETO, J.F., Ed. Farmácia Hospitalar e suas interfaces com a saúde. São Paulo: RX, 2005. cap. 12, p.175-193.

GOULD, I.M. Antibiotic polices and control of resistance. Curr. Opin. Infect. Dis., v.15, p.395-400, 2002.

HIDALGO, S.R. Análise do perfil de consumo de antimicrobianos em um hospital de ensino. São Paulo, 2003. 86p. [Dissertação de Mestrado. Departamento de Medicina - Universidade Federal de São Paulo/Escola Paulista de Medicina].
LAPORTE, J.R.; TOGNONI, G., ROZENFELD, S. Epidemiologia do medicamento: princípios gerais. São Paulo: Hucitec - Abrasco, 1989. 264 p.

LAPORTE, J.R.; TOGNONI, G. Princípios de epidemilogía del medicamento. 2.ed. Barcelona: Masson-Salvat Medicina, 1993. $271 \mathrm{p}$.

LEE, D.; BERGMAN U. Studies of drug utilization. In: STROM, B.L. Pharmacoepidemiology. 2.ed. Stamford: Willey, 1994. p.279-393.

LOEFFLER J.M.; GARBINO J.; LEW D.; HARBARTH S.; ROHNER P. Antibiotic consumption, bacterial resistance and their correlation in a Swiss University Hospital and its adult Intensive Care Units. Scand. J. Infect. Dis., v.35, p.843-850, 2003

LÓPEZ-MEDRANO, F.; SAN JUNA, R.; SERRANO, O.; CHAVES, F.; LUMBRERAS, C.; LIZASOAÍN, M.;TEJADA, A.H.; AGUADO, J.M. PACTA: Efecto de un programa no impositivo de control y asesoramiento del tratamiento antibiótico sobre la disminución de los costes y el descenso de ciertas infecciones nosocomiales. Enferm. Infecc. Microbiol. Clin., v.23, p.186-90, 2005.

MURTHY, R. Implementation of strategies to control antimicrobial resistance. Chest, v.119, p.405-411, 2001.

NÁJERA, L.H.; BLASCO, A.C.; SANZ, M.U; OSINAGA, E.A.; INCHAURREGUI, L.C.A. Trends in antimicrobial utilization at a Spanish general hospital during a 5 year period. Pharmacoepidemiol. Drug Saf., v.12, p.243-247, 2003.

SHANKAR, P.R.; PARTHA, P.; SHENOY N.; BRAHMADATHAN, K.N.; NEPAL, P. Investigation of antimicrobial use pattern in the intensive treatment unit of a teaching hospital in western Nepal. Am. J. Infect. Control, v.31, p.410-414, 2003.

Received for publication on $12^{\text {th }}$ junho 2008 Accepted for publication on $10^{\text {th }}$ october 2008 